\title{
UMA ANÁLISE DO CONCEITO DE “EU” NOS TEXTOS DE B. F. SKINNER
}

\author{
AN ANALYSIS OF “SELF” CONCEPT IN B. F. SKINNER'S TEXTS \\ GaBRIELA PIRES MALACRIDA - ORCID 0000-0003-4899-7383 \\ CAROLINA LAURENTI - ORCID 0000-0002-5247-9610 \\ UnIVERSIDADE EstaduAl de MARINGÁ - PARANÁ - BRASIL
}

\begin{abstract}
RESUMO
O projeto científico de psicologia de Skinner, pautado na filosofia do Behaviorismo Radical, surge em oposição às psicologias centradas no conceito de eu iniciador. Entretanto, as objeções do autor não parecem implicar no abandono do conceito em sua obra. O objetivo deste artigo é explicitar algumas acepções da noção de "eu" circunscritas ao texto skinneriano, que não se restringem às suas críticas à ideia de eu iniciador. $\mathrm{O}$ "eu" é entendido como um repertório verbal que descreve as condições corporais e o comportamento do próprio indivíduo, sendo construído em contingências sociais, por meio de questionamentos feitos pelos membros da comunidade verbal, que permitiram ao indivíduo voltar-se para si mesmo. Assim, no Behaviorismo Radical a noção de "si próprio" só pode ser entendida no âmbito de contingências sociais verbais, não havendo, portanto, um "eu" preexistente ao comportamento verbal. O "eu" também pode ser definido como comportamento verbal complexo, caracterizado por uma série de outros repertórios verbais (autoobservação, autodescrição, autoconhecimento, autocontrole, autogoverno, autoedição) que ajudam a criar e a manter a noção de si mesmo. À medida que se avança para a descrição desses diferentes repertórios comportamentais que definem o "eu", verifica-se um "eu" cada vez mais ativo, sem que essa atividade seja esclarecida pela noção de agente iniciador. Em suma, não há uma cisão entre "eu" e comportamento no Behaviorismo Radical; por conseguinte, as noções geralmente atribuídas ao eu iniciador (e.g., consciência, autoestima, pensamento) podem ser esclarecidas em termos do exame do comportamento e de contingências sociais verbais.
\end{abstract}

Palavras-chave: eu; eu iniciador; Behaviorismo Radical; comportamento verbal; atividade

Skinner's scientific project of psychology, based on Radical Behaviorism philosophy, arises in opposition to psychologies centered on the concept of the initiating self. However, the objections of the author do not seem to imply in abandoning the conception of self in his work. The purpose of this article is to make explicit some meanings of the notion of "self" circumscribed to the Skinnerian text, which are not restricted to his criticisms of the idea of the initiating self. The "self" is understood as a verbal repertoire that describes the body and the behavior of the individual, being constructed in social contingencies, through questioning made by the members of the verbal community, which allowed the individual to turn to himself/herself. Thus, in Radical Behaviorism the notion of "himself/herself" can only be understood in the context of verbal social contingencies; there is no pre-existing "I" to verbal behavior. "Self" can also be defined as complex verbal repertoire, characterized by a series of other verbal behaviors (self-observation, selfdescription, self-knowledge, self-control, self-government, self-editing) that help create and maintain "himself/herself". As we proceed, then, for the description of these different behavioral repertoires that make up the "self", there is an increasingly active "self", without this activity being clarified by the notion of an initiating agent. In short, there is no split between "self" and behavior in Radical Behaviorism; therefore, the notions generally attributed to the initiating self (e.g., consciousness, self-esteem, thinking) can be clarified in terms of examination of behavior and verbal social contingencies.

Key words: self; initiating self; Radical Behaviorism; verbal behavior; activity

Correspondência relativa a este artigo deve ser enviada a Gabriela Malacrida (e-mail: gaabi.maalacrida@gmail.com).

DOI. 10.18542/rebac.v14i1.7160 
O projeto de psicologia de B. F. Skinner (19041990) é caracterizado, dentre outros aspectos, por criticar formas de explicação do comportamento que recorrem à ideia de um eu iniciador ou homem autônomo, entendido como uma instância interna ao indivíduo que seria responsável por originar seus comportamentos (Chiesa, 1994/2006; Pimentel, Bandini, \& Melo, 2012).

Skinner tece uma série de críticas à noção de eu iniciador. Do ponto de vista explicativo, argumenta que usualmente as pessoas recorrem ao eu iniciador quando não conseguem identificar as variáveis contextuais das quais seu comportamento é função: "Incapazes de compreender a maneira ou a razão de uma pessoa se comportar, atribuímos seu comportamento a alguém que não podemos ver, e cujo comportamento também não podemos explicar, mas sobre o qual não estamos dispostos a fazer perguntas" (Skinner, 1971, p. 14). Diante dessa limitação, conjecturam um "eu" para explicar o comportamento, mas, segundo o autor, esse "eu" não explica; muito pelo contrário, ele cessa a explicação já que não leva a pessoa a inquirir mais além, sondando, por exemplo, a situação antecedente e as consequências que esclarecem o porquê das ações dos indivíduos: "A função da hipótese de um 'homem interior' é fornecer uma explicação que, por sua vez, não será esclarecida. A partir dela, cessa qualquer explicação" (Skinner, 1971, p. 14).

Skinner (1981) também faz objeções de natureza sociopolítica, alegando que explicar o comportamento recorrendo a um eu interior desvia o olhar das contingências sociais que são as responsáveis pela constituição e manutenção dos problemas individuais. A desconsideração das contingências sociais fomenta explicações internalistas, que culpam o indivíduo pelo seu fracasso na sociedade: "Enquanto nos apegarmos à concepção de que uma pessoa é um executor, um agente ou um causador inicial do comportamento, continuaremos provavelmente a negligenciar as condições que devem ser modificadas para que possamos resolver nossos problemas" (Skinner, 1981, p. 504).

Há, outrossim, críticas ontológicas à noção de eu iniciador. Nas explicações internalistas, o "eu" é entendido como algo de natureza diferente do comportamento: o eu iniciador pode ter uma natureza mental (mente iniciadora) ou neurofisiológica (cérebro iniciador) (Skinner, 1989a). Independentemente de sua natureza (mental ou neurofisiológica), o "eu" integraria um sistema de explicação internalista do comportamento que subscreveria uma cisão entre "eu" e comportamento. De acordo com essa lógica explicativa, o eu iniciador seria uma causa interna e o comportamento o seu efeito, isto é, a manifestação externa dessa causa. Chiesa (1994/2006) elucida esse ponto dizendo que o comportamento seria entendido como “. . . a expressão de um eu essencial ou de uma existência íntima, de um indivíduo delimitado separado e localizado atrás do comportamento" (Chiesa, 1994/2006, p. 97).

Para Chiesa (1994/2006), o projeto de psicologia de Skinner propõe uma nova forma de explicar o comportamento, que não incorre na separação entre a pessoa (ou o eu) e o comportamento. A autora argumenta ainda que, segundo Skinner, a única maneira de entender as pessoas e seus comportamentos de modo condizente com uma proposta behaviorista radical seria definir indivíduos "em termos de seus comportamentos sem nenhuma outra entidade, nenhum outro indivíduo delimitado localizado atrás" (Chiesa, 1994/2006, p. 99).

As restrições de Skinner à noção de eu iniciador ensejaram, por sua vez, uma série de objeções à sua proposta de psicologia científica (ver Carrara, 2005). O próprio Skinner parecia estar ciente delas. Em seu livro About behaviorism, ele destacou, por exemplo, que o Behaviorismo Radical fora criticado por ser uma teoria que "não atribui qualquer papel ao eu ou à consciência do eu" (Skinner, 1974b, p. 7), "desumaniza o homem" e ". . . negligencia a unicidade do indivíduo" (p. 8).

Subjaz a essas assertivas que, ao negar uma explicação do comportamento humano com base na ideia de eu iniciador, Skinner estaria, em última instância, negando a própria noção de “eu”. Skinner (1989a) esclarece esse raciocínio: "Há lugar numa análise científica do comportamento para o eu iniciador, originador, criativo? Tendo prescindido de Deus como criador, deve a ciência prescindir também da imagem de Deus chamada Homem?" (p. 27).

Além de ponderar se haveria espaço para uma acepção de "eu" em sua teoria, Skinner (1974b) contraargumenta vinte críticas feitas ao Behaviorismo Radical, citadas em About behaviorism, alegando que estariam equivocadas, inclusive a que o acusa de desconsiderar o conceito de "eu" em sua proposta de psicologia científica. Isso sugere que as objeções de Skinner ao eu iniciador não excluem, a princípio, um conceito de "eu" em sua teoria. Essa ilação ganha apoio em diferentes estudos da área que discutem conceitos atrelados à noção de "eu", tais como privacidade (Tourinho, Borba, Vichi, \& Leite, 2011), sujeito (Micheletto \& Sério, 1993), autocontrole (Bringham, 1980; Hanna \& Todorov, 2002), autoconhecimento (Brandenburg \& Weber, 2005; Day, 1969), autodescrição (Day, 1969; Lo Dico, 2018). A despeito de esses trabalhos estarem pautados na filosofia do Behaviorismo Radical, e de até avançarem algumas proposições de Skinner a respeito do assunto (e.g., Rubio, 2004; Tourinho, Borba, Vichi, \& Leite, 2011), um estudo sistemático que explore no texto do autor as suas menções à noção de "eu" [self] poderia dar subsídios para estudos futuros interessados na problemática em pauta. Considerando essa possibilidade, o objetivo deste texto é explicitar algumas acepções da noção de "eu" circunscritas ao próprio texto skinneriano, que não se restringem às suas objeções à ideia de eu iniciador ${ }^{1}$.

\section{A GÊNESE SOCIAL DO "EU"}

De acordo com Skinner (1953a), aquilo que é usualmente nomeado por "eu" pode ser entendido, de modo preliminar, como um sistema de respostas ou um conjunto de repertórios comportamentais, cuja origem é social verbal. $\mathrm{O}$ autor define comportamento verbal como um operante - isto é, como um tipo de ação que produz consequências no mundo e é afetado pelas consequências que produz (Skinner, 1957a). Skinner (1957g) declara 
ainda que o fortalecimento dessa classe de ações depende da mediação de outros indivíduos: "O comportamento verbal é reforçado apenas por meio da mediação de outra pessoa, mas não exige a participação de tal pessoa para sua execução" (p. 52). Além da mediação social do reforço, Skinner (1957a, 1957b) acrescenta que o comportamento verbal também requer um ouvinte treinado por uma comunidade verbal para se comportar em função do comportamento do falante: “o 'ouvinte' deve responder de maneiras que têm sido condicionadas precisamente no sentido de reforçar o comportamento do falante" (Skinner, 1957f, p. 225).

À luz dessas considerações, dizer que o "eu" é de origem social verbal significa que os comportamentos que definem o "eu" são constituídos por meio das relações entre o indivíduo e sua comunidade verbal. Mais especificamente, o "eu" se constrói no âmbito de contingências sociais verbais, organizadas por ouvintes que integram essa comunidade, na qual são feitos questionamentos à pessoa a respeito do que ela sentiu e fez, ou sente e faz. Ao inquirir sobre os sentimentos, por exemplo, a comunidade verbal acaba ensinando a pessoa a ficar sob controle de seu próprio corpo; ao indagar sobre as ações, são criadas condições para que o indivíduo fique sob controle de seu próprio comportamento. Ao adquirir a linguagem, a pessoa torna-se, então, capaz de falar sobre si (seu corpo e comportamento), criando-se, em última instância, a noção de si mesmo (Skinner, 1957e, 1974c, 1974e, 1989a, 1989b).

Doravante, com base nessa noção de “eu”, serão descritos alguns dos repertórios comportamentais que fazem parte daquilo que pode ser entendido como "eu" na obra skinneriana.

\section{AUTO-OBSERVAÇÃO, AUTODESCRIÇÃO E AUTOCONHECIMENTO}

Um dos repertórios comportamentais que ajudam a esclarecer a noção de "eu" é o de auto-observação:

A auto-observação é também produto de contingências discriminativas, e se a discriminação não for forçada pela comunidade, ela talvez nunca aconteça. Estranhamente, é a comunidade que ensina o sujeito a "conhecer a si mesmo". (Skinner, 1957a, p. 134)

Skinner destaca algumas razões pelas quais a comunidade verbal instrui o indivíduo a observar seu próprio comportamento e as condições corporais que o acompanham. Uma delas é que ao ensinar alguém a ficar sob controle do que acontece consigo, a comunidade verbal pode também ter acesso a essas informações, o que contribui para ampliar o seu controle sobre o comportamento do indivíduo. Segundo Skinner (1957c):

As contingências necessárias para o comportamento auto-descritivo são organizadas pela comunidade quando há motivos para perguntar "o que você disse?", "você disse isso?" ou "por que você disse isso?" e, assim por diante, pois as respostas são úteis de várias maneiras. (p. 314)

Aliado ao repertório de auto-observação, é constituído um repertório que Skinner nomeia como autodescrição, que compreende a capacidade do sujeito de falar sobre si mesmo, sobre o que faz, pensa e sente. Skinner (1953b) afirma que algumas agências de controle como psicoterapia, escola, religião e Estado, por exemplo, são responsáveis pela construção desse repertório. Para que o controle do comportamento do indivíduo por essas agências seja eficaz é necessário que o sujeito aprenda não só a observar, mas a descrever a si mesmo.

Com respeito especificamente ao ensino do repertório autodescritivo sob controle de condições corporais, Skinner (1989b) argumenta que ele é gerado quando a comunidade verbal faz perguntas sobre o que o indivíduo está sentindo, organizando contingências para que o falante nomeie essas condições. No entanto, o arranjo desse tipo de contingências é uma tarefa difícil. Entender a natureza dessa dificuldade pode ajudar a esclarecer o porquê de a linguagem a respeito dos sentimentos ser geralmente ambígua e metafórica.

Um dos obstáculos ao ensino do repertório de autodescrição sob controle de condições corporais é de natureza social, e não ontológica (isto é, o fato de o sentimento ser supostamente de natureza mental): “. . . o que é sentido ou introspectivamente observado não é nenhum mundo imaterial da consciência, da mente ou da vida mental, mas o próprio corpo do observador" (Skinner, 1974c, p. 10). É social, pois quem ensina o indivíduo a relatar suas condições corporais não tem acesso direto a elas. Skinner (1989b) declara que a dificuldade em ensinar uma criança a nomear um estado corporal - como o enjoo quando fica doente ou a nomear o que sente como alegria quando recebe um presente, por exemplo - reside no fato de que não se pode apontar e ensinar a pronunciar o nome de um desses estados como é feito com o ensino da nomeação de objetos. É possível que se ensine a nomear uma caneta esferográfica de caneta apontando para ela e apresentando-a ao sujeito, mas o mesmo não pode ser feito com uma dor de estômago, considerando que a condição corporal só pode ser "observada" pelo próprio indivíduo que a sente.

Por isso, o ensino da autodescrição pela comunidade verbal está baseado em inferências acerca do que o indivíduo está sentindo, pautando-se na observação de comportamentos (chorar, gritar) ou sinais corporais (hematomas, machucados) públicos (Skinner, 1974d, 1989b). Além disso, para o desenvolvimento de um repertório autodescritivo preciso, sob controle de condições corporais, seria necessário haver uma espécie de concordância entre as condições corporais e os eventos públicos que as geraram, algo que pode não acontecer. Skinner resume a natureza dessas dificuldades no seguinte trecho:

A comunidade verbal segue uma prática bastante semelhante ao ensinar a uma criança uma expressão como "isso dói”. Quando a criança 
recebe um golpe ou corte, o golpe ou corte público é bastante confiável associado com os estímulos privados gerados por ele. A comunidade verbal usa a informação pública, mas a criança eventualmente pode dizer "isso dói" enquanto responde apenas ao evento privado. Ela aprendeu a descrever um estímulo privado com uma precisão que depende apenas de quão bem os eventos públicos e privados estão de acordo. (Skinner, 1974d, p. 13)

$\mathrm{O}$ autor também destaca que existe uma dificuldade de natureza neurofisiológica para o ensino do autorrelato verbal sob controle de condições corporais: não há um sistema nervoso cujas inervações alcancem especificamente todas as partes do corpo. Isso impede que o sujeito consiga sentir seu corpo da mesma forma como sente o mundo externo ("fora da pele"). O indivíduo não pode, por exemplo, sentir o sangue que corre em suas veias, e nem se o faz rápido ou devagar, ou se seu estômago está digerindo o que come, visto que não existem terminações nervosas específicas para todas as regiões do corpo. Skinner (1974d, 1974e) argumenta que o sistema nervoso não evoluiu conforme a demanda da comunidade verbal por descrições precisas a respeito de condições corporais. Ele resume as duas fontes de dificuldade relacionadas ao ensino da autodescrição:

O conhecimento introspectivo do corpo autoconhecimento - é defeituoso por duas razões: a comunidade verbal não pode trazer comportamentos autodescritíveis sob o controle preciso de estímulos privados e não houve oportunidade para a evolução de um sistema nervoso, o que traria algumas partes muito importantes do corpo sob esse controle. (Skinner, 1974e, p. 86)

Embora o autorrelato verbal sob controle de condições corporais não seja inequívoco, a dimensão corporal ganha importância para esclarecer uma das acepções de "eu” destacada por Skinner (1989a). O autor admite que mesmo sem contingências sociais verbais, já existem algumas contingências, cuja função remonta presumivelmente à história evolutiva da espécie humana, que vinculam o comportamento ao corpo, criando uma consciência pré-verbal: "um organismo raramente se comporta de maneira efetiva sem responder ao seu próprio corpo. As contingências responsáveis pelo comportamento explicam esse tipo de autoestimulação" (Skinner, 1989a, p. 29); e que:

... seu próprio corpo é a única parte do ambiente que permanece a mesma (idem), momento a momento, dia após dia. Dizemos que ela [a criança] descobre sua identidade à medida que aprende a distinguir entre seu corpo e o resto do mundo. Ela aprende isso muito antes que a comunidade verbal a ensine a nomear as coisas e a distinguir entre "mim" de "isso" ou de "você". (Skinner, 1971, pp. 198-199)

No entanto, contingências diferentes envolvem o "eu". Trata-se de contingências sociais verbais especiais que levam o indivíduo a responder a partes específicas de sua estrutura corporal, de tal modo que ele não apenas responde às estimulações produzidas por seu corpo, mas a responder de acordo com as demandas de sua comunidade verbal, passando também a nomeá-las e a ficar sob controle dessa descrição. Com isso, a pessoa identifica-se com suas condições corporais. Para entender esse ponto, vale recuperar uma distinção feita por Skinner (1989a): enquanto o termo "pessoa" descreve repertórios de comportamento que podem ser observados pelos outros, o "eu", entendido como um conjunto de estados internos, "é observado apenas por meio dos sentimentos e introspecção" (p. 28). Skinner destaca que há uma diferença entre dizer "eu era uma pessoa diferente" e "não era eu mesmo" (p. 28). No primeiro caso, outros indivíduos poderiam dizer a mesma coisa com base na observação de comportamentos da pessoa sobre quem se fala; todavia, a segunda sentença sugere que a pessoa se sentiu diferente. Nesse último caso, Skinner (1989a) argumenta que "o eu é como a pessoa sente a si mesma" (p. 28). Parece haver uma identificação entre o "eu" e o corpo propiciada por contingências sociais verbais que requerem auto-observação e autodescrição.

Skinner (1989a) descreve algumas situações que ilustram como as pessoas passam a "sentir a si mesmas", de acordo com contingências sociais arranjadas pela comunidade verbal da qual fazem parte. Uma delas é a descrição da gênese do sentimento de autoestima. Esse sentimento está relacionado ao reforço apresentado pela comunidade verbal quando o sujeito se comporta de uma forma socialmente aceitável - isto é, de acordo com o que a sociedade considera útil para dar continuidade às suas práticas e, por isso, reforça este comportamento aumentando a probabilidade de que ele volte a ocorrer. No processo de reforçamento de determinados comportamentos úteis ou interessantes socialmente, condições corporais são produzidas e só podem ser observadas e descritas pela própria pessoa. Essas condições fazem com que o sujeito se sinta útil conforme é reforçado por emitir comportamentos específicos que a sociedade em que está inserido aprova. Passando a palavra a Skinner (1989a):

Uma cultura elogia e recompensa os comportamentos de seus membros que são úteis ou fazem coisas interessantes, em parte chamando-o [o sujeito] e as coisas que faz [ou seja, seus comportamentos] de boas ou certas. No processo, o comportamento é positivamente reforçado e condições corporais são geradas e podem ser observadas e avaliadas pela pessoa de quem se fala. (p. 30)

O sentimento de autoestima associado a um repertório comportamental "valorado" (reforçado 
positivamente) pela comunidade verbal pode ser exemplificado quando uma criança tira notas boas em uma prova e é considerada inteligente pelos seus pais e professores. Nessa situação, o elogio dos pais e professores, se funcionar como reforçador positivo, produz, possivelmente, dois efeitos: um corporal, a criança sente que fez algo bom (autoestima); e um comportamental, a probabilidade de comportamentos efetivos de estudo serem emitidos no futuro é aumentada.

Dizer que o sentimento de autoestima é o sentimento que a pessoa tem de si mesma pressupõe que essa pessoa seja capaz de acessar e relatar suas condições corporais (auto-observação e autodescrição), e que essas condições corporais são "dela", não só porque são percebidas e sentidas no mesmo lugar (corpo), mas porque há contingências sociais verbais que incitam a pessoa a observar e a relatar essas condições e a nomeá-las como suas, como sugerem questões como estas: "o que você está sentindo?" (Skinner, 1989b).

Auto-observação e autodescrição, por sua vez, parecem ser necessárias para o desenvolvimento de outro repertório comportamental que define o "eu", o autoconhecimento:

O autoconhecimento possui origem social. Apenas quando o mundo privado de uma pessoa se torna importante para os outros é que também se torna importante para ele [o sujeito]. Então, esse [o mundo privado] fica sob controle do comportamento chamado conhecimento. Mas o autoconhecimento possui valor para o próprio indivíduo. Uma pessoa que "tem consciência de si mesma" por meio de questões que lhe foram feitas está em uma melhor posição para prever e controlar o próprio comportamento. (Skinner, 1974a, p. 16)

$\mathrm{Na}$ perspectiva skinneriana, a descrição do próprio comportamento pelo sujeito implica que ele está consciente de sua ação. Todavia, para Skinner (1989c), existem níveis de consciência ou autoconhecimento distintos, relacionados à capacidade de o indivíduo discriminar uma série de variáveis presentes nas contingências controladoras de seu próprio comportamento, como, por exemplo, a topografia de sua ação (como age), as condições antecedentes (quando age), $\mathrm{e}$ as consequências (por que age). A noção skinneriana de autoconhecimento não se restringe, portanto, ao autorrelato verbal sob controle de condições corporais, mas se estende ao autorrelato verbal sob controle de diferentes variáveis associadas tanto às propriedades da resposta (topografia) quanto ao ambiente (antecedentes e consequências) (Skinner, 1953a, 1974a, 1974d). Na perspectiva behaviorista radical, a pessoa que se conhece é aquela capaz de relatar não só o que sente, mas como, quando e por que se comporta.

Além disso, o comportamento verbal emitido "em primeira pessoa" (autorrelatos), que descreve as variáveis das quais o comportamento do indivíduo é função, presumivelmente é reforçado não apenas pela comunidade verbal, que se beneficia desse tipo de descrição por ampliar o seu controle sobre o sujeito. Como sugere Skinner (1974a), o comportamento verbal autodescritivo, no caso o autoconhecimento, também é reforçado pelas suas consequências úteis ao indivíduo; isto é, tal comportamento permite uma melhor previsão e controle do comportamento do próprio sujeito.

No contexto dessa discussão surge a noção de “eu racional", caracterizado pelo comportamento verbal autodescritivo das razões de emissão do comportamento do indivíduo, isto é, das variáveis das quais seu comportamento é função:

Todo comportamento, efetivo ou não, é inicialmente não racional no sentido de que as contingências responsáveis por ele não foram analisadas. Todo comportamento é, em princípio, inconsciente, mas pode tornar-se consciente sem se tornar racional: uma pessoa pode saber o que está fazendo sem saber por que está fazendo. (Skinner, 1974a, p. 114)

Não basta que o indivíduo saiba o que está fazendo para que seu comportamento seja considerado racional. $\mathrm{O}$ fato de saber o que faz se concentra na questão de o comportamento ser consciente; para se tornar racional é necessário também que ele consiga falar a respeito das razões (variáveis controladoras) de agir dessa forma - isto é, tornando o comportamento consciente e racional. Um exemplo disso é um adolescente que consegue descrever que lava a louça antes de sua mãe chegar em casa, mas não é capaz de relatar o porquê. De acordo com a lógica skinneriana, nesse exemplo, o comportamento do adolescente seria consciente, mas não racional. Ao analisar funcionalmente seu comportamento, ele conseguiria descrever que organiza a cozinha antes da chegada da mãe porque, assim, evita que ela brigue com ele por não ter feito nada durante a tarde - nesse sentido, o sujeito se comporta com a função de se esquivar de um evento aversivo, sendo seu comportamento reforçado negativamente. Esse adolescente estaria em melhor posição para prever e controlar o próprio comportamento. A capacidade de fazer uma análise funcional de seu comportamento, descrevendo as "razões" de sua ocorrência, estabelece, portanto, o campo da racionalidade. O sujeito não sabe só que se comporta, mas também porque se comporta.

Contudo, a dificuldade tanto para a comunidade verbal quanto para o próprio indivíduo de identificar e acessar todas as variáveis das quais o comportamento é função parece impossibilitar que o "eu" seja totalmente consciente e racional - ainda mais se as perguntas que a comunidade verbal faz para o sujeito se limitarem ao escrutínio de suas condições corporais, em detrimento das variáveis contextuais.

\section{AUTOCONTROLE, AUTOGOVERNO E AUTOEDIÇÃO}

O comportamento de conhecer a si mesmo (autoconhecimento) - isto é, de descrever verbalmente 
outros comportamentos e estados internos do próprio indivíduo, bem como as variáveis das quais esses comportamentos e estados internos são função ("eu" racional) - é necessário para que outro repertório que constitui o "eu" se estabeleça: o autocontrole. Tradicionalmente, a noção de autocontrole é esclarecida com base na ideia de uma força interna (ou força de vontade), sob a ação da qual o indivíduo seria capaz de evitar a exposição a eventos aversivos, em especial, em longo prazo. De acordo com essa concepção, o indivíduo se autodeterminaria, "escolhendo", de acordo com sua razão, o melhor caminho a ser trilhado (Skinner, 1953c). Trata-se de uma noção mentalista de autocontrole, na medida em que a explicação residiria em causas internas ao indivíduo (força de vontade), ignorando a relação do sujeito com as variáveis controladoras de seu comportamento.

A despeito de criticar o conceito tradicional de autocontrole, Skinner (1953c) não abandona a noção de que o indivíduo "escolhe"; no entanto, essa escolha não é entendida como sendo produto do exercício de uma faculdade interna denominada razão. Escolher deliberadamente implica em alterar a probabilidade de ocorrência de um dado tipo de ação pela manipulação das variáveis das quais esse comportamento é função. A discussão do autocontrole é propícia para ilustrar essa tese. Segundo Skinner (1953c), o autocontrole é útil quando o sujeito precisa controlar parte de seu comportamento que tem consequências que "provocam conflitos". A ingestão de bebidas alcóolicas é um exemplo. Skinner afirma que, em curto prazo, ocorrem consequências socialmente reforçadoras (perda da vergonha e pertencimento social), mas, em longo prazo (como no dia seguinte), a ressaca pode ser vista como uma consequência aversiva tardia do comportamento de exagerar no consumo de álcool. Com isso, é necessário que o sujeito esteja sob controle de seu comportamento e altere variáveis com a função de evitar os estímulos aversivos condicionados e as respostas emocionais associadas a eles.

Conforme o sujeito manipula as variáveis das quais seu comportamento é função, a resposta punida se torna menos frequente, considerando que alguns comportamentos são automaticamente reforçados pela redução da estimulação aversiva. Segundo Skinner (1953c), o repertório de autocontrole é útil ao sujeito para que ele possa discriminar os contextos em que se comporta, lidando com a maior probabilidade de reforçamento em alguns casos e com a redução de punições em outros. Nesse sentido, o autocontrole é um repertório de mudança do próprio comportamento por meio da alteração de variáveis presentes no ambiente, de forma que o sujeito muda o ambiente para mudar seu próprio comportamento, lançando mão de técnicas de autocontrole (sobre exemplos de diversas técnicas de autocontrole, ver Skinner, 1953c). Isto significa que o indivíduo altera variáveis como o contexto, a consequência ou a topografia de seu comportamento para, então, poder se comportar de forma mais eficaz, produzindo reforçadores positivos e evitando estímulos aversivos em longo prazo.
Na discussão skinneriana do autocontrole, o "eu" apresenta um caráter ativo: um "eu controlador", entendido como um repertório de comportamentos que altera o ambiente com a função de mudar outro repertório, o "eu controlado", caracterizado pelos comportamentos que produziam "conflitos". No entanto, o caráter ativo do "eu controlador" não se confunde com a noção de eu iniciador, entendido como uma causa autônoma, que age independentemente das relações do indivíduo com seu contexto. Isso porque esse "eu controlador" é de origem social, ou seja, é um repertório comportamental aprendido com a comunidade verbal; trata-se, pois, de uma atividade contextualizada no mundo (mudando estímulos antecedentes e consequentes), e não malgrado o mundo. Ademais, esse "eu controlador" não pode ser confundido com uma entidade interna iniciadora (a razão), pois esse "eu controlador" é de natureza comportamental; o "eu controlador" é "racional" apenas no sentido de que envolve também um repertório verbal autodescritivo das variáveis das quais o comportamento do sujeito é função.

Outro repertório útil para exemplificar a noção skinneriana de "eu" é o autogoverno, que se aproxima da função do autocontrole, mas está relacionado a atividades cognitivas, no sentido do estabelecimento de uma autonomia intelectual. Como já foi mencionado no início deste texto, a noção de "eu iniciador" geralmente é invocada quando as variáveis contextuais das quais o comportamento do indivíduo é função não são identificadas. No caso do autogoverno intelectual, encontrar a solução para um problema ou "ter uma ideia" são entendidos, em uma lógica mentalista, como o produto da atividade de um "eu iniciador". Mas, à semelhança do autocontrole, o autogoverno intelectual não é esclarecido por meio das atividades de um "eu" interior. Segundo Skinner (1968b), o autogoverno pode ser entendido como uma classe de comportamentos úteis, possibilitando que o sujeito manipule o ambiente ou outro comportamento verbal para aumentar a probabilidade de emitir respostas que sejam compatíveis com a resolução de problemas. O autor declara: "Outras contingências verbais geram o comportamento chamado autogoverno ou pensamento, em que os problemas são resolvidos manipulando contingências (como na resolução prática de problemas) ou regras (como no 'raciocínio')" (Skinner, 1989c, p. 63).

Tal como no caso do autocontrole, o repertório de autogoverno também é ensinado por uma comunidade verbal, em particular, pelo professor que deveria criar condições para que o aluno "aprenda a pensar": "É importante que o aluno aprenda sem ser ensinado, que resolva problemas sozinho, que explore o desconhecido, tome decisões, que se comporte de maneira original, e estas atividades devem, se possível, ser ensinadas" (Skinner, 1968a, p. 123-124). A função do professor não seria a de fornecer a resposta correta ou dar a solução de um problema, mas sim, ensinar técnicas de autogoverno, de modo que o aluno, por si mesmo, altere o ambiente e o seu próprio comportamento aumentando as chances de encontrar a solução para o problema.

Assim, tanto o processo de resolução de problemas algorítmicos (cuja solução já é conhecida) 
quanto o de resolução de problemas heurísticos (cuja solução não é conhecida) são explicados, em alguma medida, pelo uso de técnicas de autogoverno intelectual por parte do aluno, que foram ensinadas por uma comunidade verbal (professores). Mais especificamente, para Skinner (1968a), as técnicas de autogoverno estão relacionadas à originalidade de uma ideia, considerando que promovem a alteração ou aumento da efetividade do comportamento. Ao se deparar

... com uma situação para a qual não há comportamento eficiente disponível (na qual não podemos emitir uma resposta que seja provavelmente reforçada), comportamo-nos de maneiras que tornam possível o comportamento eficiente (melhoramos nossas chances de reforço). Ao fazê-lo, tecnicamente falando, executamos uma resposta "preliminar" que muda ou o ambiente ou a gente mesmo, de forma tal que o comportamento "consumatório" ocorra. (Skinner, 1968a, p. 127)

Nos processos de resolução de problemas ou de "ter" uma ideia, algumas dessas respostas preliminares podem ser encobertas, o que pode lançar luz sobre a dificuldade de se identificar as variáveis envolvidas nesses processos, abrindo o flanco para que causas mentais sejam invocadas como explicação. Tais respostas encobertas presumivelmente foram reforçadas, no passado, por estarem associadas a outros comportamentos que produziram a solução de um problema (Skinner, 1968a, 1968b).

Outro processo intelectual usualmente explicado em termos do "eu iniciador" é a criatividade: o comportamento novo ou criativo seria entendido como produto de uma "mente criativa". No entanto, novamente, Skinner (1968b) prescinde do "eu iniciador" para explicar esses comportamentos, argumentando que o comportamento criativo pode ser entendido como produto de um arranjo de contingências imprevisíveis. A despeito disso, o próprio estudante poderia aumentar as suas chances de emitir comportamentos criativos valendo-se de técnicas que contribuam para a produção de variabilidade comportamental, condição necessária para a produção de comportamentos novos. Uma dessas técnicas, por exemplo, envolve o uso de metáforas: quando um professor ensina o aluno a resolver problemas de uma forma que já existe este não fornece contexto para que o aluno aprenda a resolvê-los de sua própria maneira. Nesse sentido, não há generalização, isto é, o aluno não resolverá todos os problemas se for ensinada a ele uma fórmula que não permite que ele compreenda o que está fazendo, apenas a aplique mecanicamente em um contexto específico (Skinner, 1968b). A ideia de Skinner (1968b) para o uso de metáforas é que o sujeito aplique o conhecimento em diferentes situações e não só naquelas em que já vira exemplos de utilização. Para o autor (1968b),
Em certo sentido, o aluno pode saber muito bem o que sabe. Não generalizará prontamente se a topografia de seu comportamento for agudamente definida ou se estímulos específicos estiverem no controle. Um poeta terá maior tendência a usar metáforas e a engajar-se em outras formas de jogo verbal se tiver um grande vocabulário, mas as palavras deste vocabulário não devem estar muito rigidamente ligadas a ocasiões específicas. Os cientistas definem os termos que usam tão precisamente quanto possível; metáforas poéticas não são encontradas com frequência nas suas publicações técnicas, mas grande parte do pensar científico é, não obstante, metafórica no sentido de que as expressões aprendidas em uma situação são generalizadas para outras; isto não ocorrerá se os termos forem estritamente controlados. (p. 175)

Valendo-se de metáforas o estudante pode ampliar a sua variabilidade comportamental, ficando sob controle de diferentes estímulos ou de relações entre estímulos, aumentando as chances de se produzir um comportamento novo.

A ideia de autogoverno pode também ser esclarecida tendo como base os operantes verbais analisados funcionalmente por Skinner em Verbal behavior (1957a). Diante das definições dadas pelo autor para os operantes verbais (Skinner, 1957g), é possível compreender que existe uma estreita relação entre o repertório de autogoverno e a possibilidade de o sujeito emitir os operantes verbais para manejar seu comportamento de pensar. Para exemplificar esse ponto, Skinner (1957c) lança mão da noção de autoclíticos: um comportamento verbal que está sob controle da audiência, sendo utilizado para mudar outro comportamento verbal com a função de aumentar a probabilidade de produzir reforçamento e evitar punições.

As respostas verbais descritas e manipuladas pelo falante com autoclíticos apropriados aumentam e modelam seu efeito sobre o ouvinte. Muitas vezes elas também são examinadas por seus efeitos sobre o falante ou sobre o ouvinte em perspectiva, e, em seguida, rejeitadas ou liberadas. Esse processo de "correção" constitui uma atividade adicional ao falante. (Skinner, 1957d, p. 443)

Skinner (1957d) declara que, com isso, "o falante testa seu comportamento em si próprio antes de apresentálo ao ouvinte" (p. 370). O autoclítico tem uma função importante por possibilitar que o sujeito se esquive de eventos aversivos diminuindo a probabilidade de ocorrência de respostas punidas e, assim, se comporte de uma forma diferente.

Tendo em vista a ideia de que os autoclíticos são conjuntos de operantes verbais que modificam o efeito de outros, Skinner (1957d) destaca que se trata de uma classe de comportamentos verbais de segunda ordem: "o termo autoclítico tem a intenção de sugerir um comportamento 
que está baseado ou depende de outro comportamento verbal" (Skinner, 1957c, p. 315) -, como no caso de o indivíduo pensar a respeito de uma fala durante o debate e, antes de se pronunciar, rever o que pretende dizer. Por meio desse processo, o falante pode corrigir possíveis falhas em seu discurso antes de emiti-lo abertamente, compreendendo, então, o que Skinner (1957d) denomina como capacidade de auto editar-se. A noção de autoclítico, em última instância, ajudaria a esclarecer a própria visão comportamentalista de pensamento:

O falante e o ouvinte dentro da mesma pele se envolvem em atividades tradicionalmente descritas como "pensamento". O falante manipula seu comportamento; ele o revisa e pode rejeitá-lo ou emiti-lo em forma modificada. A medida que ele faz varia em uma ampla gama, determinada em parte pela medida em que ele serve como seu próprio ouvinte. $\mathrm{O}$ orador hábil aprende a provocar comportamentos fracos e manipular variáveis que irão gerar e fortalecer novas respostas em seu repertório. (Skinner 1957a, p. 11)

Com a noção de autogoverno intelectual, Skinner explica uma série de atividades usualmente atreladas ao conceito de "eu iniciador", como resolução de problemas, criatividade, pensamento. Além disso, o fazer "por si próprio" que diz respeito à noção de autonomia intelectual envolve repertórios comportamentais complexos, mas cuja complexidade não é explicada pela atividade de um "eu autônomo". Diferentemente disso, esses repertórios foram modelados pela comunidade verbal por meio do ensino de técnicas que permitem ao estudante maximizar a produção de reforçadores (resolução de problemas algorítmicos), descobrir novos reforçadores positivos (resolução de problemas heurísticos), ampliar a sua variabilidade comportamental (criatividade), emitir respostas encobertas associadas a comportamentos públicos que produzem reforçadores positivos e evitam estímulos aversivos (pensamento).

\section{UM EU ATIVO NO BEHAVIORISMO RADICAL}

Com base no exame de algumas menções de Skinner à noção de "eu" é possível concluir que sua crítica ao eu iniciador não implica na negação do "eu" no Behaviorismo Radical. Na ótica skinneriana, o "eu" consiste em um repertório verbal que descreve as condições corporais e o comportamento do próprio indivíduo, sendo construído por meio de contingências sociais arranjadas por uma comunidade verbal (Skinner, 1953a, 1953d, 1968a, 1968b), mediante questionamentos que permitiram que o indivíduo voltasse para si (para o seu corpo e comportamentos). Assim, a perspectiva em primeira pessoa, ou a noção de "si próprio" (self), só se dá em contingências sociais verbais. Isso significa que não há um "eu" que preexiste ao comportamento verbal.

A dimensão corporal ganha relevo na elucidação da noção de "eu" no Behaviorismo Radical, pois o "eu" é, em uma acepção preliminar, como a pessoa sente a si mesma. Essa identificação do indivíduo com seu corpo dáse em contingências sociais verbais que incitam o sujeito a ficar sob controle de suas condições corporais, nomeandoas e ficando também sob controle dessa descrição. Mas a noção de "si próprio" não é só construída com o desenvolvimento de repertórios que permitam o indivíduo a ficar sob controle de suas condições corporais, mas também do seu próprio comportamento (auto-observação). Nesse caso, as perguntas feitas pela comunidade verbal a respeito do que o sujeito fez ou faz (topografia), quando fez ou faz (situação antecedente) e por que fez ou faz (consequências) criam condições para que o indivíduo relate não só o "seu" comportamento (autodescrição), mas também as variáveis das quais seu comportamento é função (autoconhecimento). A comunidade verbal não apenas ensina o indivíduo a descrever o seu comportamento com níveis de consciência distintos, mas a modificá-lo por meio do ensino de técnicas de autocontrole e de autogoverno intelectual.

Em suma, o "eu" é também comportamento verbal complexo, definido por uma série repertórios verbais (auto-observação, autodescrição, autoconhecimento, autocontrole, autogoverno, autoedição) que ajudam a criar e a manter a noção de "si mesmo". (Além disso, há de se considerar que a manutenção da noção de "si mesmo" é dada por reforçamento social: a frequência de emissão do comportamento verbal em primeira pessoa ("eu") é mantida pelo reforçamento arranjado pela própria comunidade verbal, que se beneficia do autorrelato do indivíduo ampliando o seu controle sobre ele. A emissão de autorrelatos descritivos das variáveis controladoras do comportamento é reforçada, igualmente, pelas consequências úteis geradas ao indivíduo, pois ele também passa a ter um maior controle e previsão do seu próprio comportamento.)

À medida que se avança para a descrição dos diferentes repertórios comportamentais verbais que constituem o "eu" (auto-observação, autodescrição, autoconhecimento, autocontrole, autogoverno, autoedição), verifica-se um “eu” cada vez mais ativo, sem que essa atividade seja esclarecida pela noção agente iniciador. De acordo com a tese do eu iniciador, o "eu" é ativo, porque é uma causa interna autônoma (mentalista ou neurofisiológica) responsável pelo comportamento do indivíduo. Já no Behaviorismo Radical o "eu" é ativo porque é, antes de tudo, comportamento verbal, que é operante: é ação que produz consequências no mundo e é afetada pelas consequências que produz. Esse "eu" é ativo porque a comunidade verbal ensina comportamentos que capacitam o indivíduo a mudar o seu próprio comportamento (e.g., autocontrole, autogoverno e autoedição), por meio de alterações feitas, por ele mesmo, no ambiente; e também alterar suas próprias condições corporais, manipulando contingências responsáveis por elas. Assim, é nessa relação recursiva entre indivíduo e mundo social que o "eu” se constitui. Não há, portanto, uma cisão entre "eu” e comportamento no Behaviorismo Radical. Ainda que o "eu" seja um produto do ambiente, por ser constituído em contingências sociais verbais, não se trata necessariamente de um produto passivo. 


\section{DECLARAÇÃO DE CONFLITO DE INTERESSES}

As autoras declaram que não há qualquer conflito de interesses relativos à publicação deste artigo.

\section{CONTRIBUIÇÃO DE CADA AUTORA}

Certificamos que todas as autoras participaram suficientemente do trabalho para tornar pública sua responsabilidade pelo conteúdo. A contribuição de cada autora pode ser atribuída como se segue: G. P. Malacrida e C. Laurenti contribuíram para a concepção do artigo; G. P. Malacrida fez a coleta de dados; C. Laurenti foi responsável pela formulação do design metodológico; G. Malacrida e C. Laurenti foram responsáveis pela redação final.

\section{DIREITOS AUTORAIS}

Este é um artigo aberto e pode ser reproduzido livremente, distribuído, transmitido ou modificado, por qualquer pessoa desde que usado sem fins comerciais. $\mathrm{O}$ trabalho é disponibilizado sob a licença Creative Commons 4.0 BY-NC.

\section{$(\mathrm{cc}) \overline{\mathrm{EY}-\mathrm{NC}}$}

\section{REFERÊNCIAS}

Brandenburg, O. J., \& Weber, L. N. D. (2005). Autoconhecimento e liberdade no behaviorismo radical. PsicoUSF, 10(1), 87-92.

Brigham, T. A. (1980). Self-control revisited: Or why doesn't anyone actually read Skinner (1953). The Behavior Analyst, 3(2), 25-33.

Carrara, K. (2005). Behaviorismo radical: Crítica e metacrítica ( $2 \mathrm{a}$ ed. rev. amp.). São Paulo: Editora UNESP.

Chiesa, M. (2006). As concepções de causa. In Behaviorismo radical: A filosofia e a ciência (pp. 96121). Brasília: Editora Celeiro. (Trabalho original publicado em 1994).

Day, W. F. (1969). Radical behaviorism in reconciliation with phenomenology. Journal of the Experimental Analysis of Behavior, 12(2), 315-328. doi: 10.1901/1969.12-315.

Hanna, E. S., \& Todorov, J. C. (2002). Modelos de autocontrole na análise experimental do comportamento: Utilidade e crítica. Psicologia: Teoria e Pesquisa, 18(3), 337-343. doi: 10.1590/S010237722002000300014.

Lo Dico, G. (2018). Self-perception theory, radical behaviourism and the publicity/privacy issue. Review of Philosophy and Psychology, 9(2), 429-445. doi: 10.1007/s13164-017-0378-8.

Micheletto, N., \& Sério, T. M. de A. P. (1993). Homem: Objeto ou sujeito para Skinner? Temas em Psicologia, 1(2), 11-21.

Pimentel, N. dos S., Bandini, C. S. M., \& Melo, C. M. (2012). Compreendendo o abandono do "eu iniciador" em B. F. Skinner a partir das críticas de G. Ryle ao mentalismo tradicional: Questões teóricas e consequências práticas. Acta Comportamentalia, 20(2), 217-233.
Rubio, A. R. (2004). Behaviorismo radical: Uma revisão do conceito de self na obra de B. F. Skinner (Vol. 13, pp. 12-20). In M. Z. da S Brandão et al. (Orgs.), Sobre comportamento e cognição: Contingências $e$ metacontingências - contextos socioverbais $e$ o comportamento do terapeuta. Santo André: ESETec.

Skinner, B. F. (1953a). Culture and control. In Science and human behavior (pp. 415-425). New York: The Macmillan Company.

Skinner, B. F. (1953b). Group control. In Science and human behavior (pp. 323-331). New York: The Macmillan Company.

Skinner, B. F. (1953c). Self-control. In Science and human behavior (pp. 227-241). New York: The Macmillan Company

Skinner, B. F. (1953d). The self. In Science and human behavior (pp. 283-295). New York: The Macmillan Company.

Skinner, B. F. (1957a). A functional analysis of verbal behavior. In Verbal behavior (pp. 1-12). Massachusetts: Copley Publishing Group.

Skinner, B. F. (1957b). General problems. In Verbal behavior (pp. 13-34). Massachusetts: Copley Publishing Group.

Skinner, B. F. (1957c). The autoclitic. In Verbal behavior (pp. 311-330). Massachusetts: Copley Publishing Group.

Skinner, B. F. (1957d). The self-editing. In Verbal behavior (pp. 369-383). Massachusetts: Copley Publishing Group.

Skinner, B. F. (1957e). The tact. In Verbal behavior (pp. 81-146). Massachusetts: Copley Publishing Group.

Skinner, B. F. (1957f). The verbal operant as a unit of analysis. In Verbal behavior (pp. 185-226). Massachusetts: Copley Publishing Group.

Skinner, B. F. (1957g). Verbal behavior under control of verbal stimuli. In Verbal behavior (pp. 52-80). Massachusetts: Copley Publishing Group.

Skinner, B. F. (1968a). Teaching thinking. In The technology of teaching (pp. 123-146). New York: Meredith Corporation.

Skinner, B. F. (1968b). The creative student. In The technology of teaching (pp. 166-188). New York: Meredith Corporation.

Skinner, B. F. (1971). Beyond freedom and dignity. Middlesex: Penguin Books.

Skinner, B. F. (1974a). Causes and reasons. In About behaviorism (pp. 49-55). New York: Vintage Books.

Skinner, B. F. (1974b). Introduction. In About behaviorism (pp. 7-12). New York: Vintage Books.

Skinner, B. F. (1974c). The causes of behavior. In About behaviorism (pp. 8-12). New York: Vintage Books.

Skinner, B. F. (1974d). The world within the skin. In About behaviorism (pp. 13-17). New York: Vintage Books.

Skinner, B.F. (1974e). Summing up. In About behaviorism (pp. 86-97). New York: Vintage Books.

Skinner, B. F. (1981). Selection by consequences. Science, 213(4507), 501-504. 
Skinner, B. F. (1989a). The initiating self. In Recent issues in the analysis of behavior (pp. 27-33). Columbus: Merrill Publishing Company.

Skinner, B. F. (1989b). The place of feeling in the analysis of behavior. In Recent issues in the analysis of behavior (pp. 3-12). Columbus: Merrill Publishing Company.

Skinner, B. F. (1989c). Whatever happened to psychology as the science of behavior? In Recent issues in the analysis of behavior (pp. 59-72). Columbus: Merrill Publishing Company.

Tourinho, E. Z., Borba, A., Vichi, C., \& Leite, F. L. (2011). Contributions of contingencies in modern societies to "privacy" in the behavioral relations of cognition and emotion. The Behavior Analyst, 34(2), 171-180.

\section{Nota de fim}

1 Este artigo é produto de parte uma pesquisa de natureza conceitual desenvolvida no âmbito do Programa de Iniciação Científica da Universidade Estadual de Maringá, intitulada "Os usos do termo eu na obra de B. F. Skinner" (processo n. 1828/2017). A pesquisa foi dividida em três etapas. Na primeira, com o intuito de avaliar a crítica skinneriana ao eu iniciador, foram rastreados, por meio da ferramenta CTRL $+\mathrm{F}$, os termos "initiating agent", "initiating self", “initiating man", "autonomous man", "autonomous agent", “inner agent”, “inner man”, “inner self", "doer" e "agency" nos livros digitalizados de Skinner em língua original (inglês). Os resultados foram sistematizados em forma de tabelas, cujas entradas especificavam: referência; reprodução do trecho literal, com indicação de parágrafo e página em que as expressões supracitadas ocorriam; e comentários sobre os trechos. Os capítulos em que a ocorrência de um ou mais termos fosse superior a dez apresentações o texto fora lido integralmente. $\mathrm{Na}$ segunda etapa, os referenciais de seleção foram os conceitos "self" e "selves", seguindo-se o mesmo procedimento de sistematização realizado na etapa 1. O objetivo desta etapa era rastrear os usos do termo "eu" em Skinner que não estavam atrelados à sua crítica à noção de eu iniciador. Por fim, fora construído um texto que arrolou as principais críticas à noção de eu iniciador, bem como as principais acepções behavioristas radicais da noção de "eu". O texto em pauta foi elaborado com base nos resultados da etapa 2 .

Submetido em: 07/08/2018 Aceito em: 25/01/2019 